\title{
A study on effects of knowledge management on organizational entrepreneurship: A case study of educational system
}

\author{
Naser Azad $^{\mathrm{a}}$ and Esmaeil Mehrabi Majolan ${ }^{\mathrm{b}^{*}}$
}

${ }^{a}$ Department of Management, Islamic Azad University, South Tehran Branch, Tehran, Iran

${ }^{b}$ Department of Management, Islamic Azad University, Arak Branch, Arak, Iran

\begin{tabular}{|c|c|}
\hline ARTICLEINFO & A B S T R A C T \\
\hline $\begin{array}{l}\text { Article history: } \\
\text { Received March 25, } 2012 \\
\text { Received in revised format } \\
25 \text { September } 2012 \\
\text { Accepted } 8 \text { October } 2012 \\
\text { Available online } \\
\text { October } 142012 \\
\text { Keywords: } \\
\text { Structural equation modeling } \\
\text { Knowledge management } \\
\text { Change management }\end{array}$ & $\begin{array}{l}\text { Knowledge management plays an important role in business development especially in } \\
\text { educational system. The proposed study designs and distributes a questionnaire among experts } \\
\text { who are involved in education systems in province of Tehran, Iran. The population of this } \\
\text { survey includes } 1680 \text { people who are enrolled in administration levels of this province and } \\
\text { using a simple sapling technique is calculated as } 313 \text {. The questionnaire consists of } 30 \\
\text { questions in Likert scale and there are six categories for the proposed study of this paper } \\
\text { including the concept of knowledge, management, knowledge tools, knowledge measurement, } \\
\text { change management, knowledge content. We have used LISREL software package to find the } \\
\text { relationship between entrepreneurship and knowledge management components. Based on the } \\
\text { results of this survey, knowledge content is number one priority followed by knowledge tools } \\
\text { and concept of knowledge. The other factors including management, knowledge measurement } \\
\text { and change management are in lower levels of importance. }\end{array}$ \\
\hline
\end{tabular}

\section{Introduction}

Knowledge management (KM) plays an important role on business development and there are literally many works associated with investigation on the relevant importance of KM in organizations (Stoner et al., 1995; Perez, 1999; Scarbrough \& Swan, 2001; Monavvarian\& Kasaei, 2007). Darroch (2005) performed an empirical investigation on KM implementation for a real-world case study and concluded that a firm with a KM capability will use resources more efficiently and so will be more innovative and perform better. Du plessis (2005) tried to understand what drives KM in today's business environment by considering characteristics of the inherent objective of KM and by analyzing the necessity for fulfillment of these objectives to provide some solutions as to why KM is considered as a significant value contributor in today's business world. Some of the drivers of KM include geographically dispersed work environments, the need for quick and efficient decision-making the

* Corresponding author.

E-mail addresses: amirmehrabi338@gmail.com (E. Mehrabi Majolan) 
increased volume of knowledge available to organizations, the advent of new technologies including the Internet, and knowledge attrition.

Hurley (1999) explained that feminist critiques could provide new insights into organizational theories by investigating the historical context in which these theories are combined. Hurley implemented a feminist critique to sociological theories of entrepreneurship. She explained the sociological theories focusing on the impacts of political factors, state policies, culture, spatial location, and professionalization on entrepreneurship (Lober, 1998; Landstrom, 2005). Mcfadyen and Canneila (2004) analyzed the relationship between knowledge creation and social capital at an individual level. They reported that interpersonal relationship has important impact on knowledge creation. Antony and Bhattacharyya (2010) proposed a conceptual model for measuring organizational performance and organizational excellence, which could be implemented by small and medium enterprises. They recommended various excellences and equations for calculating overall organizational performance and overall organizational excellence. Lustri et al. (2007) investigated KM conceptual model for competency development and a considering a real-world case study from law service firm. They reported that within a certain amount of time, participants in their survey who received some KM lessons could improve their skills.

Antoncic and Prodan (2008) presented a firm performance model, which concentrated on corporate technological entrepreneurship (CTE) via alliances and networks. They recommended that firms should involve in strategic alliances to develop corporate technological entrepreneurship activities and gain performance improvements to build better infrastructure for their business units. Ray (2008) performed another investigation to determine the requirement for $\mathrm{KM}$ in a business driving information technology.

Raub and von wittich (2004) determined three strategies for effective CKOs and reported that successful implementation of MK needs aligning the contributions of key organizational actors, promoting the development of knowledge networks and providing support by delivering a purposeful message. Rutherford and Holt (2007) Used a sample of 264 employees of a mid-sized organization and conceptualized three antecedent categories of CE: including process, context, and individual characteristics. They also examined the mediating effect of $\mathrm{CE}$ on desirable individual outcomes including job satisfaction, turnover intent, and affective commitment. Their results indicated that the model did a sufficient job of explaining $\mathrm{CE}$, and that $\mathrm{CE}$ mediated the relationship between their antecedents and individual outcomes. According to Petrakis (2005), entrepreneurial behavior to exploit the resources within a firm is a tool to maintain competitive advantage and improve financial performance. He performed an investigation to determine the determinants of such entrepreneurial behavior, which exist in Indian firms. He verified that firms with entrepreneurial behavior had a distinct improved financial performance. Snyman and Kruger (2004) tried to supply strategic thinkers with a holistic "bird's eye view" of the interdependency between strategic management and strategic MK. They developed a generic model incorporating KM strategy formulation within business strategy formulation has been developed.

The organization of this paper first presents the proposed study and hypotheses in section 2 . Section 3 explains the results of the implementation of structural equation modeling and finally, concluding remarks are given in the last to summarize the contribution of this paper.

\section{The proposed study}

The proposed study designs and distributes a questionnaire among experts in this field. The population of this survey includes 1680 people who are enrolled in administration levels of province of Tehran, Iran and the proposed study of this paper used the following formula to calculate the minimum number of sample size, 
$n=\frac{N \times z_{\alpha / 2}^{2} \times p \times q}{\varepsilon^{2} \times(N-1)+z_{\alpha / 2}^{2} \times p \times q}$,

where $N$ is the population size, $p=1-q$ represents the yes/no categories, $z_{\alpha / 2}$ is CDF of normal distribution and finally $\varepsilon$ is the error term. Since we have $p=0.5, z_{\alpha / 2}=1.96$ and $N=1680$, the number of sample size is calculated as $n=313$. The questionnaire consists of 30 questions in Likert scale in terms of very much (5) to very low (1). There are six categories for the proposed study of this paper including the concept of knowledge, management, knowledge tools, knowledge measurement, change management, knowledge content. Table 1 shows means and standard deviations of the data.

\section{The results}

\section{Table 1}

Mean and standard deviation

\begin{tabular}{lccc}
\hline $\begin{array}{l}\text { The effects of knowledge management on organizational } \\
\text { entrepreneurship }\end{array}$ & Mean & Standard deviation & Rank \\
\hline Concept of knowledge & 3.98 & 0.71 & 1 \\
Management & 3.95 & 0.7 & 2 \\
Knowledge tools & 3.95 & 0.72 & 3 \\
Knowledge measurement & 3.93 & 0.73 & 4 \\
Change management & 3.9 & 0.7 & 5 \\
Knowledge content & 3.94 & 0.72 & 6 \\
\hline
\end{tabular}

Before we perform factor analysis, we need to validate the data using KMO Bartlet test. The implementation of this test yields a KMO value of 0.946 with Chi-Square value of 18964.67 with 3741 degree of freedom and P-value of 0.000 . The results indicate that the correlation matrix among different components is not unique and there is a strong correlation from one side and no correlation from the other side. The implementation of factor analysis is summarized in Table 2 as follows,

Table 2

Statistical observation for the implementation of factor analysis

\begin{tabular}{lllllll}
\hline Statistics & Chi-Square & $\mathrm{df}$ & Chi-Square/df & RMSEA & GFI & AGFI \\
\hline Value & 14.48 & 9 & 1.6 & 0.044 & 0.98 & 0.96 \\
\hline
\end{tabular}

As we can observe from the results of Table 2, Chi-square/df is equal to 1.6, which is well below a critical value of 3 and it shows the model maintains a good fitness. RMSEA is also equal to 0.044 and it must be less than a critical value of 0.08 , GFI is equal to 0.98 and it is well above the minimum desirable level of 0.9 , finally, AGFI is equal to 0.96 , which is acceptable.

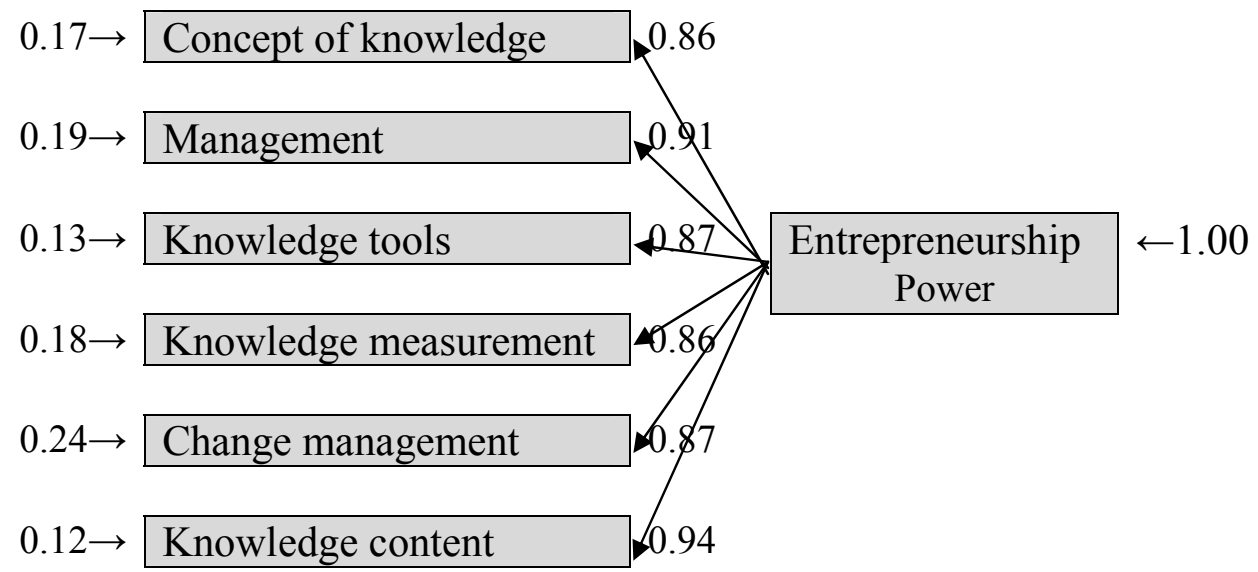

Chi-square $=14.48, \mathrm{df}=9, \mathrm{P}-$ Value $=0.10618, \mathrm{RMSEA}=0.044$

Fig. 1. The results of factor analysis in non-standard form 
As we can observe from the results of Fig. 1, the data seem to fit well with what we expect in realworld. Now, we can make estimations for standard model. Fig. 2 shows details of our findings.

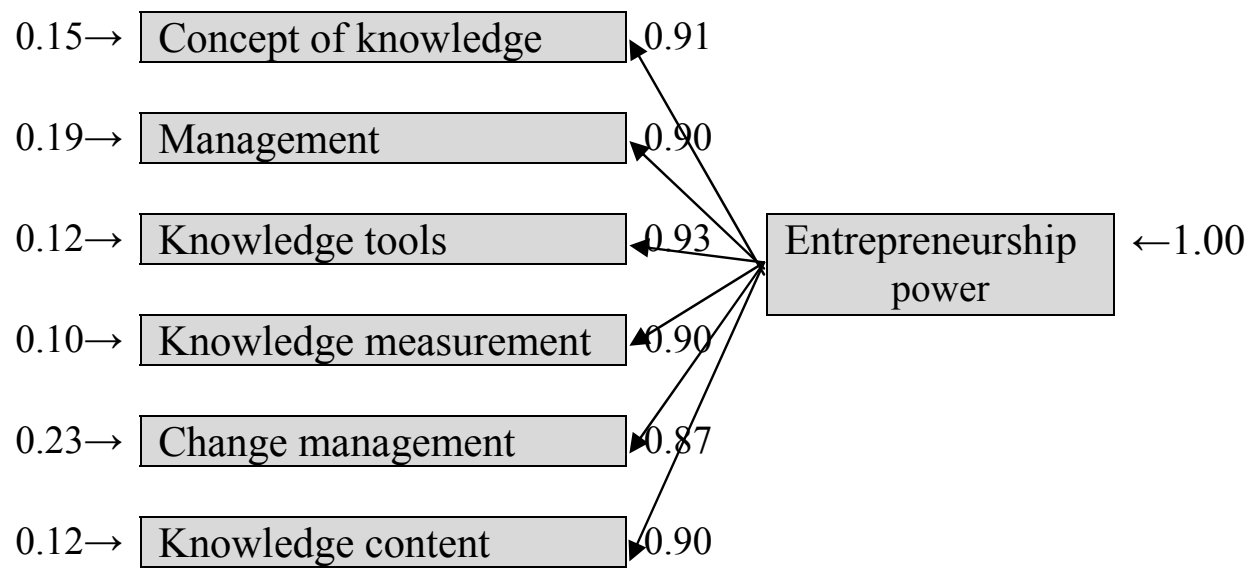

Chi-square $=14.48, \mathrm{df}=9, \mathrm{P}-$ Value $=0.10618$, RMSEA $=0.044$

Fig. 2. The results of factor analysis in standard form

Finally, we need to consider t-student values to verify the whole model. Fig. 3 presents details of our findings for t-student values.

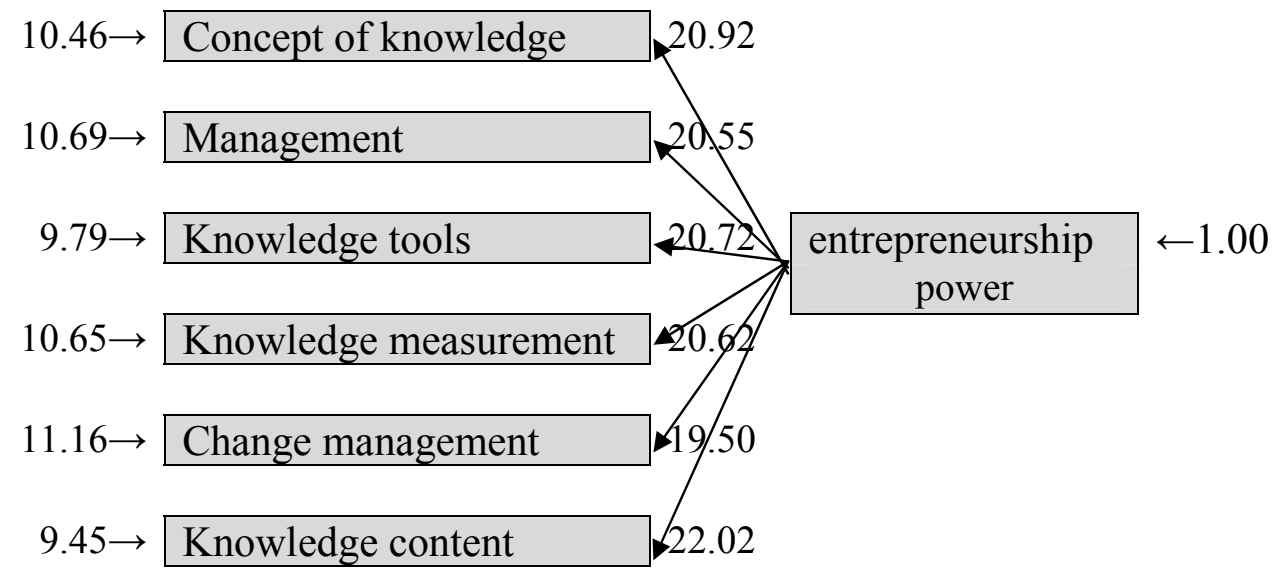

Chi-square $=14.48, \mathrm{df}=9, \mathrm{P}-$ Value $=0.10618, \mathrm{RMSEA}=0.044$

Fig. 3. The results of t-values for factor analysis in standard form

The results of t-values are well above the critical value of 1.96 when the level of significance is five percent. Therefore, we can conclude that the results represent the effects of entrepreneurship power on six items. Table 3 summarizes the results of our survey along with the ranking of different items.

\section{Table 3}

The results of the effects knowledge management on organizational entrepreneurship

\begin{tabular}{lccrr}
\hline $\begin{array}{l}\text { The effects of knowledge management on } \\
\text { organizational entrepreneurship }\end{array}$ & $\begin{array}{c}\text { Non-standard } \\
\text { coefficient }\end{array}$ & $\begin{array}{c}\text { Standard } \\
\text { coefficient }\end{array}$ & P-value & Rank \\
\hline Concept of knowledge & 0.86 & 0.91 & 20.93 & 3 \\
Management & 0.91 & 0.90 & 20.55 & 4 \\
Knowledge tools & 0.87 & 0.93 & 21.73 & 2 \\
Knowledge measurement & 0.85 & 0.90 & 20.62 & 5 \\
Change management & 0.87 & 0.87 & 19.50 & 6 \\
Knowledge content & 0.90 & 0.94 & 22.02 & 1 \\
\hline
\end{tabular}


As we can observe from the results of Table 3, knowledge content is number one priority followed by knowledge tools and concept of knowledge. The other factors including management, knowledge measurement and change management are in lower levels of importance.

\section{Conclusion}

In this paper, we have presented an empirical study to find the relationship between entrepreneurship and other knowledge management components. We have used LISREL software package to find the relationship between entrepreneurship and knowledge management components. Based on the results of this survey, knowledge content is number one priority followed by knowledge tools and concept of knowledge. The other factors including management, knowledge measurement and change management are in lower levels of importance.

\section{Acknowledgment}

The authors are grateful for constructive comments on earlier version of this paper. We would like to also acknowledge the financial support of Islamic Azad University of Iran.

\section{References}

Antoncic, B. \& Prodan, I. (2008). Alliances, corporate technological entrepreneurship and firm performance: Testing a model on manufacturing firms. Technovation, 28, 257-265.

Antony, J.P., \& Bhattacharyya, S. (2010). Measuring organizational performance and organizational excellence of SMEs - Part 1: a conceptual framework. Measuring Business Excellence, 14(2), 311.

Darroch, J. (2005). Knowledge management, innovation and firm performance. Journal of Knowledge Management, 9(3), 101-115.

Du plessis, M. (2005). Drivers of knowledge management in the corporate environment. International Journal of Information Management, 25, 193-202.

Hurley, A. E. (1999). Incorporating feminist theories in to sociological theories of entrepreneurship. Women in Management Review, 14(2), 54-62.

Mcfadyen, M. A. \& Canneila, A.A. (2004). Social capital \& knowledge creation: Diminishing return of the number and strength of exchange relationship. Academy of Management Journal, 47(5), 735-746.

Monavvarian, A., \& Kasaei, M. ( 2007). A KM model for public administration: the case of Labour Ministry. The journal of information and knowledge management systems, 37(3), 348-367.

Landstrom, H. (2005). Pioneers in Entrepreneurship and small Business Research methods: Historical Approach. Springer, Boston.

Lober, D.J. (1998) Pollution prevention as corporate entrepreneurship. Journal of Organizational Change Management,11(1), 26-37.

Lustri, D., Miura, I., \& Takahashi, S. (2007). Knowledge management model: practical application for competency development. The Learning Organization, 14(2), 186-202.

Ray, L. (2008). Requirement for knowledge management: business driving information technology. Journal of knowledge management. 12(3), 3-17.

Raub, S. \& von wittich, D. (2004). Implementing knowledge management: Three strategies for effective CKOS. European Management Journal, 22(6), 714- 724.

Rutherford, M. W., \& Holt, D. T. (2007). An empirical look at the innovativeness dimension and its antecedents. Journal of organizational Chang Management, 20(3), 429-446.

Perez, E. (1999). Knowledge Management in the Library-not. Database Magazine, 22(2), 75-78.

Petrakis, P. E. (2005), Risk perception, risk propensity and entrepreneurial behavior: the Greece case. The Journal of American Academy of Business, 7(1), 233-242.

Scarbrough, H. \& Swan, J. (2001). Explaining the diffusion of knowledge management: the role of fashion. British Journal of Management, 12, 3-12. 
Snyman, R., \& Kruger, C.J. (2004). The interdependency between strategic management \& strategic knowledge management. Journal of knowledge management, 8(1), 5-19 .

Stoner, J., Freeman, E., \& Gilbert, D. (1995). Management, New York: Prentice Hall Publishers. 